INVESTIGACIÓN

Recibido: 16/03/2021 --- Aceptado: 16/03/2021 --- Publicado: 24/05/2021

\title{
LA FICCIÓN EN BÚSQUEDA DEL REALISMO. UN ANÁLISIS DE “LOS FAVORITOS DE MIDAS (2020)": PERIODISMO, POLÍTICA Y CONTRAPODER
}

\author{
Fiction in search of realism. An analysis of "the minions of midas \\ (2020)": journalism, politics and counter-power
}

(8) $\mathbb{R}^{\mathrm{G}}$ Alicia Gil-Torres': Universidad de Valladolid. España. alicia.gil@uva.es

\section{Cómo citar el artículo:}

Gil-Torres, A. (2021). La ficción en búsqueda del realismo. Un análisis de "Los Favoritos de Midas (2020)": periodismo, política y contrapoder. Vivat Academia. Revista de Comunicación, 154, 95-117. http://doi.org/10.15178/va.2021.154.e1339

http://www.vivatacademia.net/index.php/vivat/article/view/1338

\section{RESUMEN}

El entretenimiento ocupa un lugar predominante en la sociedad actual, ya sea por el desplazamiento de la información y la producción de un híbrido denominado infoentretenimiento o como bienes y servicios multimedia para consumo inmediato o en diferido. En este último grupo, Netflix -que llegó a nuestro país en 2015- se erige como la plataforma de streaming con más suscriptores en España (Expansión, 2020). Además de servir para la compra de productos audiovisuales es productora de series, documentales y películas originales creadas y rodadas en diferentes países. En noviembre de 2020 lanzó una de sus últimas producciones: la miniserie limitada "Los favoritos de Midas", que centra el caso de estudio. A través de una metodología cualitativa fundamentada en estudios anteriores de otros autores y aportaciones propias, se genera una ficha de análisis para examinar el conjunto de esta propuesta argumental (no tan) ficticia a través de cuatro grandes dimensiones: personajes, escenarios, contextos y acciones. De esta manera se pretende descubrir si el proceso de construcción figurado de las situaciones mostradas y de los personajes se corresponden con patrones de la realidad. Además, el periodismo, elemento recurrente en la ficción española, es en numerosas ocasiones el hilo conductor de algunas de las tramas ya sea recurriendo a periodistas, a códigos éticos o a imperios

\footnotetext{
${ }^{1}$ Nombre y Apellidos del autor de referencia: Doctora en Periodismo (Premio Extraordinario) y Máster en Consultoría Política. Profesora Ayudante Doctor en la UVa.
} 
Gil-Torres, A.

La ficción en búsqueda del realismo. Un análisis de "Los Favoritos de Midas (2020)": periodismo, política y contrapoder

mediáticos. Los resultados reflejan que acudir a elementos reales para dar verosimilitud a la ficción es un recurso patente y que el periodista sigue constatándose como un protagonista de peso ejerciendo como contrapeso al poder en las historias que involucran asuntos políticos.

PALABRAS CLAVE: Los favoritos de Midas - Netflix - periodismo - política contrapoder - series españolas - análisis personajes - ficción - efecto de realidad.

\section{ABSTRACT}

Entertainment occupies a predominant place in today's society, either through the displacement of information and the production of a hybrid called infotainment or as multimedia goods and services for immediate or deferred consumption. In the latter group, Netflix -which arrived in our country in 2015- stands as the streaming platform with the most subscribers in Spain (Expansión, 2020). In addition to serving for the purchase of audiovisual products, it is a producer of series, documentaries and original films created and shot in different countries. In November 2020 it launched one of its latest productions: the limited miniseries "Los favoritos de Midas" (The Minions of Midas), which is the focus of the case study. Through a qualitative methodology based on previous studies by other authors and own contributions, an analysis sheet is generated to examine the whole of this (not so) fictional plot proposal through four major dimensions: characters, scenarios, contexts and actions. In this way, the aim is to discover whether the process of figurative construction of the situations shown and the characters correspond to patterns of reality. Moreover, journalism, a recurrent element in Spanish fiction, is on numerous occasions the guiding thread of some of the plots, either by resorting to journalists, ethical codes or media empires. The results reflect that resorting to real elements to give verisimilitude to fiction is a patent resource and that the journalist continues to be a major protagonist acting as a counterweight to power in stories involving political issues.

KEYWORDS: The minions of Midas - Netflix - journalism - politics - counter-power - Spanish series - character analysis- fiction - reality effect.

\section{INTRODUCCIÓN. LA REALIDAD EN LA FICCIÓN}

Las formas de consumo mediático están evolucionando y muestra de ello es el crecimiento que experimentan las plataformas de streaming o Video on Demand (VoD) en los últimos años debido a la "televisión hiperpersonalizada, al consumo compulsivo de contenidos, el visionado en movilidad y en múltiples pantallas, la fragmentación de audiencias y atención dividida o al boom de las series y de los programas fenómeno que se olvidan casi tan rápido como se consumen" (Neira, 2020: 16). El sector del entretenimiento se fija en la pequeña pantalla e impera una guerra entre las plataformas de streaming con sus catálogos, producciones propias y estrategias de precios. El año 2020 estuvo marcado por una pandemia mundial que ayudó a su 
Gil-Torres, A.

La ficción en búsqueda del realismo. Un análisis de "Los Favoritos de Midas (2020)": periodismo, política y contrapoder

incremento en cerca de 35 millones de nuevas altas. Se estima que en Europa occidental habrá 191 millones de suscripciones de VOD (SVOD) en 2025 lo que supone más del doble de los 90 millones de finales de 2019, siendo Netflix la plataforma más grande, con 68,49 millones de abonados previstos para 2025 a pesar de perder cuota de mercado (Digital TV Research, 2020).

En este aumento de suscripciones influye el lanzamiento en bloque de las series que propulsa el llamado binge-watch: "los maratones generan mucha más fidelización porque llevan a usar más horas el servicio. Favorecen reacciones mucho más viscerales si la serie tiene buena acogida. La gente quiere comentar el contenido. Se genera mucha más resonancia y eso es lo que persigue Netflix" (Bejerano, 2020), estrenando contenidos continuamente. No obstante, esta dinámica de estrenos constantes conlleva una vida fugaz de las producciones.

En 2015 se produjeron 38 series en España y en 2018, 58, pero se necesitaría una creación de 72 producciones al año para hablar de un mercado consolidado (Audiovisual451, 2019). Una de estas últimas series producidas en España es Los favoritos de Midas (2020), objeto de estudio de esta investigación, pero la primera elaboración de Netflix en nuestro país fue Las chicas del cable en 2017. En 2018 tres ficciones de las 20 más vistas en Netflix fueron españolas y solo Estados Unidos tenía más producciones en esta lista. La Casa de Papel ha sido la serie más visionada en esta plataforma en lengua no inglesa a nivel mundial (Audiovisual451, 2019).

\subsection{Representaciones sociales y estereotipos}

Debido a la necesidad de desarrollar procesos colectivos de construcción de la realidad surge el modelo de las representaciones sociales de Moscovici (1986) y sus referencias a fenómenos sociales pertenecientes a la conciencia colectiva de la sociedad (Rodríguez Salazar, 2009). Las primeras nociones en las que se basa esta teoría beben de las conceptualizaciones del sociólogo Émile Durkheim (n.1858- m.1817), quien afirmaba que las sociedades sienten la necesidad de organizar su pensamiento. Las colectividades aglutinan el pensamiento imperante y lo transmite a sus integrantes. De esta manera, el individuo, cuando incorpora el pensamiento colectivo, pasa a ser persona al haber asimilado creencias, valores, normas, etc., de esa sociedad. Así es como Durkheim (2016) intuía que el pensamiento social irradiado en cada una de las personas creaba las representaciones colectivas. Durkheim consideraba que existe una conciencia colectiva que se plasma de manera particular en la mente de cada individuo, dado que las representaciones sociales, si bien son elaboradas colectivamente, son matizadas e individualizadas por cada persona (Padilla Pineda, 1990).

De esta manera, los integrantes de una comunidad comparten un código de comunicación común para denominar la realidad en la que viven y conformar la forma en la que actúan en sociedad porque así se establecen los límites y normas que rigen en esa conciencia colectiva. Con esto asumido, todas las personas alcanzan una 
Gil-Torres, A.

La ficción en búsqueda del realismo. Un análisis de "Los Favoritos de Midas (2020)": periodismo, política y contrapoder

percepción común de lo que es la realidad que les permite, a su vez, actuar en relación con ella. Moscovici trabajó nociones que brindan contribuciones significativas para los estudios sobre los medios. Una de esas ideas es que los medios poseen la capacidad de transformar lo extraño en familiar mediante la incorporación de novedades que servirán como apoyos para comprender los cambios contemporáneos (Moscovici y Hewstone, 1986).

González Gabaldón (1999) señalaba que el ser humano, ante una necesidad natural de simplificación y distribución de su entorno, suele categorizar y apela a la generalización para facilitarle la comprensión del mundo. Mediante la simplificación se buscan similitudes en el ambiente para limitar el esfuerzo que le lleva asimilar percepciones. Desde este enfoque, el estereotipo es una cuestión de economía mental porque las generalizaciones surgen ante la imposibilidad de formar una imagen particular de cada objeto o persona. De esta manera se fundan los estereotipos: generalizaciones inexactas y simplistas sobre grupos de individuos para tratarlos de manera rutinaria conforme a las expectativas creadas (Malgesini y Giménez Romero, 2000)

Aunque la teoría de las representaciones sociales no ha sido empleada como base para el estudio de series de ficción, es interesante su enfoque porque estas "serían tanto el resultado de los procesos comunicativos que emergen de las instituciones mediáticas como de aquellos que surgen en las interacciones sociales cotidianas. En ambos casos, las representaciones sociales son productos socioculturales, estructuras significantes que emanan de la sociedad y que nos informan sobre sus características" (Rodríguez Salazar, 2009). De esta manera, esta investigación tiene su germen en la pregunta de por qué las series de ficción nos resultan tan familiares, ya sean españolas o extranjeras.

\subsection{El efecto realidad}

El 19 de septiembre de 1994 arrancó una serie de largo recorrido (331 capítulos) con un gran valor etnográfico y altos niveles documentales considerándose uno de los clásicos del lenguaje de televisión: ER (Urgencias). La serie se desarrolla en el Hospital Cook County General (posteriormente County General) de Chicago (EE. UU.), siendo el Hospital John H. Stroger Jr. de Cook County y ubicado en el mismo espacio que el ficticio centro hospitalario de la serie en la que se basaron los creadores. Todos los acontecimientos médicos se crean a partir de casos reales recogidos de las urgencias de hospitales de todo Estados Unidos. Los guionistas acudían a las salas de espera para empaparse de la dinámica de trabajo y así imprimir un realismo creíble además de tener a personal médico que les asesoraba en cada capítulo. (Chicago Tribune, 2009). Es tal la importancia de la serie ER que su narrativa se registra como un fenómeno característico de la nueva televisión (Comelles y Brigidi, 2016): destrucción voluntaria de los límites entre realidad y ficción, que daría lugar a un nivel de realidad distinto, el «efecto de realidad» (Glevarec, 2010). 
Gil-Torres, A.

La ficción en búsqueda del realismo. Un análisis de "Los Favoritos de Midas (2020)": periodismo, política y contrapoder

Desde la perspectiva de la retórica, la descripción que se realiza en las obras tiene como propósito una función estética para embellecer el relato y no está ligada a una verosimilitud referencial. Sin embargo, las descripciones que realiza Gustave Flaubert en muchas de sus obras -Madame Bovary, por ejemplo- corresponden a pautas culturales de la representación y a ciertos "imperativos realistas a partir de los cuales la exactitud del referente justifica la denotación o descripción” (Barthes, 1994: p.182). Desde el enfoque del realismo se defiende que la función estética proporciona, a la vez que delimita, el sentido como elemento importante en la descripción y que la comprensión del referente como realidad permite la objetividad del discurso realista (Barthes, 1994).

Cuando se emplea un detalle concreto en un discurso realista se genera una correspondencia directa entre el referente y el significante de Saussure (1916) creando "una ilusión referencial" donde "el significado queda expulsado del signo, y con él, por supuesto, la posibilidad de desarrollar una forma de sentido" (Barthes, 1994: p. 186). Esta ilusión es válida porque "lo concreto" borra el significado denotativo en el discurso realista para convertirse en un significado de connotación ya que "en el mismo momento en que esos detalles se supone que denotan directamente lo real, no hacen otra cosa que significarlo, sin decirlo" (Barthes, 1994: 186). De esta manera, las descripciones realistas significan a la situación creando el efecto de realidad que es la "base de esa verosimilitud inconfesada que forma la estética de todas las obras más comunes de la modernidad" (Barthes, 1994: p.186).

La representación de la realidad es una constante que se ve reflejada en las obras escritas, sobre todo las de temática histórica, donde la referencia esencial son los hechos acontecidos. Sin embargo, en los relatos de ficción la representación está sujeta a la lógica. Aunque Barthes propone la noción del efecto realidad en un marco de análisis estructural literario, se puede trasladar a los productos audiovisuales, como Glevarec (2010), quien estudia cómo las series norteamericanas desde los años 90 han llevado al límite la realidad en la ficción creando sus propios niveles de realidad. Este autor señala que el efecto de la realidad es ese punto de contacto de la diégesis ficcional con el tiempo real y social o con el mundo situado y fechado ligado a una configuración histórica. Sin duda, podríamos simetrizar las dos líneas altas y bajas para dar cuenta de lo que seguirá, a saber, que la ficción toca al mundo tanto como esta última toca a la ficción, ya que la ficción de ahora en adelante tiende a "caer" en el mundo y viceversa. El efecto de la realidad ocurre siempre que un universo diegético representacional (ficción o marco ordinario) llega a "tocar" el mundo real. Es posible proporcionar una comprensión gráfica de la misma utilizando la siguiente imagen (Glevarec, 2010): 
La ficción en búsqueda del realismo. Un análisis de "Los Favoritos de Midas (2020)": periodismo, política y contrapoder

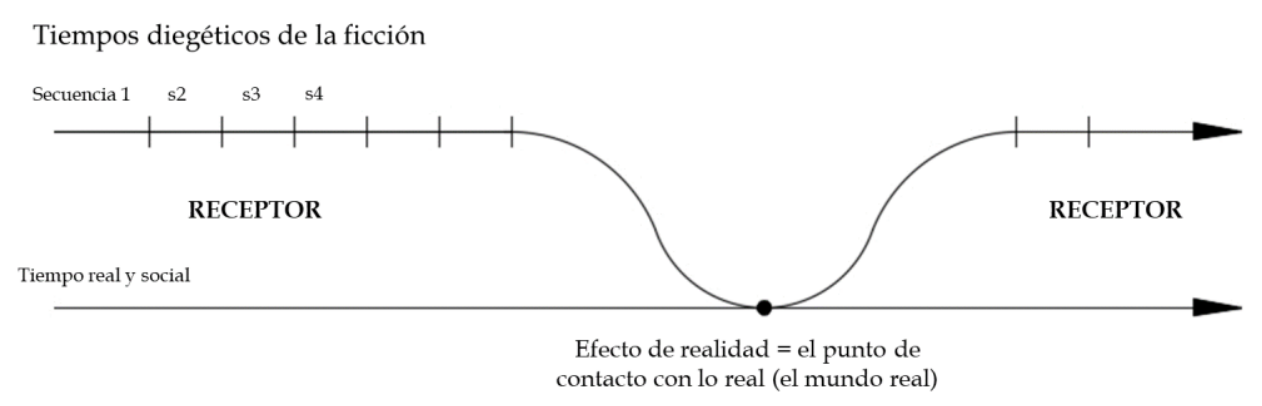

Figura 1: Ilustración del efecto de la realidad como punto de contacto Fuente: elaboración propia traducida de Glevarec (2010)

En vista de esta tesis, la categoría de realismo, y quizás incluso la de ficción, parece inadecuada para dar cuenta de la naturaleza y el funcionamiento de la ficción serial contemporánea. La noción del efecto de la realidad permite la diferenciación del realismo y la impresión de realidad. El realismo designa una relación con lo real, siempre revisable y abierta a la crítica mientras que el efecto de lo real se debe a un juego en el marco de la experiencia movilizada. Este efecto de la realidad juega con dos disposiciones confrontadas:

1. Interno o externo. Por un lado, se obtiene un efecto real de carácter pragmático (este es el caso del cross-over) y por otro, un efecto perlocucionario (ver el efecto en un receptor) de un acto de ficción (al insertar hechos del mundo real en una ficción).

2. "Pragmático" o "cognitivo". Por un lado, el medio se borra como medio, por otro, juega con sus marcos interpretativos, cuestionando los trasfondos del consumo televisivo (Glevarec, 1999).

3. Jugar con los códigos y convenciones televisivas o jugar con los marcos de interpretación. Mientras que el realismo designa una relación de correspondencia entre representación y realidad, el efecto de realidad designa una relación de inserción de lo real en la representación, su punto de contacto.

Para comprobar este efecto de la realidad en la ficción, la serie aquí considerada como objeto de estudio es española, así como su marco de recepción (autora) para intentar compartir al máximo los mismos códigos, marcos interpretativos, estereotipos, representaciones sociales y lugares geográficos. Es este espacio compartido el que define el campo relevante para los consumidores de los contenidos mediáticos (Bermejo y Núñez, 2008).

\section{OBJETIVOS}

El objetivo principal de esta investigación es descubrir si el proceso de construcción figurado de los personajes y las situaciones y circunstancias mostradas de la miniserie "Los favoritos de Midas" (2020) se corresponden con patrones de la realidad. En esa búsqueda de posibles paralelismos con la situación española, lo que se pretende es 
Gil-Torres, A.

La ficción en búsqueda del realismo. Un análisis de "Los Favoritos de Midas (2020)": periodismo, política y contrapoder

buscar correspondencias con el contexto político social y mediático de España y la ficción mostrada en la pantalla planteando una exploración cualitativa que plantea cuatro focos de investigación $\mathrm{u}$ objetivos secundarios.

$\mathrm{PI}_{1}$ ¿ ¿Qué rasgos poseen los personajes sobre los que recae algún tipo de acción? Esta cuestión se abordó desde un análisis del perfil de personajes y elementos personificados.


una enumeración y la localización de escenarios.

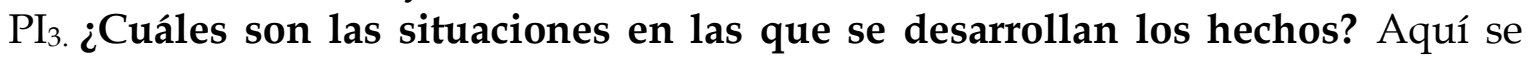
busca la revelación del contexto.

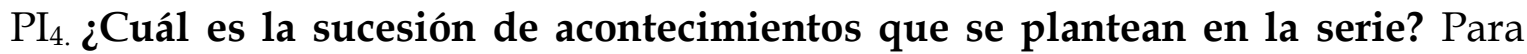
responder a esta pregunta la presentación de las acciones es clave.

Las cuatro cuestiones anteriores definen el triple frente de esta investigación. El primero de ellos es el análisis de personajes y sus elementos característicos. En segundo lugar, se busca identificar la relación espacio-tiempo. Y, por último, observar los elementos y factores que definen cómo la ficción ha optado por dotar de realismo a su narrativa u obra. De esta manera, las hipótesis que se esbozan para el análisis de "Los favoritos de Midas" son:

$\mathrm{H}_{1}$. La ficción necesita apoyarse en marcos reales existente en la vida real para la creación de un contexto y personajes que simulen una verdad para lograr un mayor éxito.

$\mathrm{H}_{2}$. El papel del periodista en la ficción española sigue mostrándose como un elemento de contrapoder.

\section{METODOLOGÍA}

Para dar respuesta a esta triangulación de intereses de la investigación se propone una metodología de carácter cualitativo-descriptivo ad hoc a partir de otros autores para dar respuesta a la $\mathrm{PI}_{1}$, pero a las $\mathrm{PI}_{2}, \mathrm{PI}_{3}$ y $\mathrm{PI}_{4}$ se propone una metodología propia debido a la singularidad del tema de estudio que se aborda en esta investigación.

Primeramente, se procedió al primer visionado de la serie, que consta de 6 capítulos con un sumatorio total de 316 minutos (5 horas y 2 minutos), en los días 23, 24 y 25 de noviembre de 2020 y no se leyó ninguna crítica sobre ella para no interferir en su asimilación. Posteriormente se percibió cómo la ficción destilaba el efecto de realidad explicado en la introducción y se ajustaba al modelo de las representaciones sociales y los estereotipos. Consecutivamente, para la codificación, y por motivos operativos, se optó por una plantilla inicial conjunta que englobara las cuatro preguntas de investigación y que permitiera su depuración durante el nuevo visionado de los capítulos. 
Gil-Torres, A.

La ficción en búsqueda del realismo. Un análisis de "Los Favoritos de Midas (2020)": periodismo, política y contrapoder

Para la $\mathrm{PI}_{1}$, fue necesario un análisis del perfil de personajes y elementos "personificados". Estos se englobaron en 4 categorías: periodismo y medios de comunicación; política y poder; contrapoder y sociedad/otros. En este punto se ha optado por asimilar las propuestas metodológicas de varios autores para encajarlos de tal modo que se adapte a la investigación propuesta.

Para la clasificación de la tipología de los personajes se acude a Fernández y Bassinger (1996) dependiendo de las funciones que desarrollarán en la evolución de las tramas. En la esfera de los roles principales están los "protagonistas y los antagonistas", que llevan el peso de la narración, y «los personajes de interés romántico», que acarrean una historia romántica con los protagonistas llegando, incluso, a interferir en el progreso de la historia. Asimismo, existen «los personajes de apoyo», que actúan ayudando al desarrollo de la acción, y que están simbolizados por "una gran variedad de personajes en la ficción audiovisual: «el confidente», «el catalizador», «de masa o peso», «de contraste», «el divertido», «de función temática», «que expresan un punto de vista» o «de equilibrio»" (Gosscordón Cortecero, 2019).

A su vez, la categorización principal se articuló en torno a las tres dimensiones que definió Egri (1946), autor de referencia para autores contemporáneos: física, psicológica y social.

1) Dimensión física. Elementos que le vienen dados al personaje: nombre, edad, aspecto físico, salud, sexo o nacionalidad, por ejemplo.

2) Dimensión psicológica. Aspectos de la personalidad y carácter que conforman el modo de pensar, sentir y actuar de los caracteres.

a) Personalidad. De acuerdo con otros autores (Egri, 1946; Field, 1984, DiMaggio, 1992 y Serger, 1990 y 1999) puede ser extrovertida (sociables y expresivos) o introvertida (tímidos y reservados).

b) Temperamento. Según Jung (2008) existen cuatro funciones vitales en todo ser humano: inteligencia, sensibilidad, percepción e intuición. Para Hirsh y Kummerow (1998) el temperamento se divide en sensorial, intuitivo, racional y emocional. Para Jung, el pensar significa tener un conocimiento amplio; el sentir, poseer la capacidad de empatía y el sentido de lo bueno y lo malo; el percibir, estar anclado en la realidad y tener cierta dosis de pragmatismo; y la intuición, tener una comprensión profunda del por qué y para qué (Galán Fajardo, 2006).

c) Objetivos. Los fines que cada personaje quiere alcanzar mediante las acciones que se desarrollan. Se clasifican como psicológicos, profesionales o personales.

3) Dimensión sociológica. Espacios en los que el personaje interactúa con otros y el contexto histórico social en el que se imbuye. Galán Fajardo (2006) propone una división de acuerdo a las relaciones familiares (estado civil, número de hijos...), profesionales (profesión, rango en la escala laboral, nivel de estudios...) y el marco espacio-temporal (trabajo, vivienda, otros...). Se añade la estabilidad en las relaciones dependiendo si varían desde el inicio de la serie o si se 
Gil-Torres, A.

La ficción en búsqueda del realismo. Un análisis de "Los Favoritos de Midas (2020)": periodismo, política y contrapoder

mantienen estancas. También se engloba la religión, lugar que ocupa en la comunidad y las aficiones (Grossocordón Cortercero, 2019).

A los arquetipos universales más repetidos propuestos por Agapito-Mesta (2016) para las producciones literarias o audiovisuales se unen las características y cualidades que concretan a cada rol en la ficción (Grossocordón Cortercero, 2019: p. 14): 1) Inocente (sencillo, sensible y auténtico); 2) Padre o rey (de autoridad, sabio y precavido); 3) Sabio (maestro y experto); 4) Explorador (aventurero); 5) Héroe o guerrero (entregado, incondicional y sacrificado); 6) Rebelde (libre, exhibicionista y hedonista); 7) Mago (creativo, obsesionado y controlador); 8) Amante (apasionado, romántico y seductor); 9) Hombre normal (sociable y respetuoso); 10) Bromista (espontáneo y alegre); 11) Embaucador (prima sus intereses personales); 12) Madre o reina (sabia, protectora y empática); 13) Protector (ofrece ayuda solo por beneficio propio); 14) Creador (perseverante y perfeccionista); y 15) Soberano (de espíritu líder e independiente).

Respecto a los arcos de transformación, se acude a Sánchez-Escalonilla (2001) y así clasificar qué trasformaciones pueden experimentar los personajes en una película pero que serán aplicados a la serie: (1) arco plano, (2) transformación radical -puede que desestabilice al personaje o quizá no modifica su temperamento previo-, (3) los arcos moderados, (4) los arcos traumáticos y (5) las transformaciones circulares del personaje.

Para la clasificación de los estereotipos se acude a su enfoque psicológico como generalizaciones para simplificar la información externa percibida por los individuos de Tajfel (1984), quien considera más importante la estructura general y la función del estereotipo al ser capaces de originar las tradiciones culturales que el propio contenido. Esta estructuración posee un aspecto cognitivo dividido en: categorización (la segmentación del todo social en subconjuntos concretos y constantes); comparación social (enfrentamiento simbólico o social entre las partes fraccionadas) y asignación de características (otorgamiento de contenidos estables que evidencian la categorización señalada).

En el análisis concreto de los personajes del mundo del periodismo, se toma el modelo de San José de la Rosa (2017) donde el retrato del periodista posee una doble vertiente, como personaje y como profesional. Esta autora se basó en Propp (1971) para confeccionar una morfología de los profesionales de los medios de comunicación para proceder a su identificación mediante 21 funciones extraídas de 135 películas con periodistas durante más de siete décadas. Estas 21 se agrupan en tres esferas: (1) según la sección en la que desempeña su profesión con 9 funciones, (2) según la personalidad del periodista, 7 funciones y (3) según se consideren héroes o villanos, 5 funciones (San José-de la Rosa y Gil-Torres, 2019). Además, no se olvida a Casetti y Di Chio (2007) quienes se apoyan en la aplicación en la literatura de esenciales en la narrativa audiovisual como de Chatman, Greimas o Propp. Atendiendo a su clasificación se 
Gil-Torres, A.

La ficción en búsqueda del realismo. Un análisis de "Los Favoritos de Midas (2020)": periodismo, política y contrapoder

hablará de periodista activo/pasivo, influenciador/autónomo o modificador/conservador.

La localización de escenarios es la clave para responder a la $\mathrm{PI}_{2}$. Por ello, gracias a su nombramiento dentro del guion y a conocimientos propios de la ciudad madrileña se puede establecer la lista de los lugares relevantes en el desarrollo de la serie. Se contactó con la productora de la miniserie, pero no hubo respuesta alguna.

Para la $\mathrm{PI}_{3}$ fue ineludible detectar el contexto de las tramas para descubrir los entornos de situación en los cuales se desarrollan los hechos. En este apartado se considera con especial atención el papel que desempeña el periodismo y por qué es tan recurrente en la cinematografía (San José-de la Rosa, 2017).

Respecto a la presentación de las acciones de la $\mathrm{PI}_{4}$ se trata de describir el curso de acontecimientos y sucesos que constituyen el argumento de la serie. De nuevo se recurre a la división de las pericias en cuatro grupos según su relación: periodísticas, políticas y el poder, el contrapoder y sociales/humanas. Aquí se trata, además, de evidenciar si el hilo argumental principal es el periodismo y cómo este es o no transversal en todos los capítulos siendo el protagonista en casi todas las secuencias.

De esta manera, con la historia descubierta, los términos de espacio-tiempo reconocidos y los elementos que envuelven a los personajes detallados se pueden identificar los componentes que esta serie de ficción ha elegido para conferir el realismo a su producto audiovisual.

\section{RESULTADOS}

Antes de proceder con los resultados y para situar la miniserie, se hace preciso señalar que la ficción audiovisual analizada versa sobre la historia de un hombre (Víctor Genovés) que recibe por herencia la presidencia de un gran grupo mediático en España. Un día recibe una carta lacrada y firmada por "Los favoritos de Midas". En ella le piden un pago de 50 millones o empezará a morir gente al azar. Durante 6 capítulos se asiste a cómo el protagonista se niega a realizar los pagos y personas inocentes mueren en circunstancias que pasan por muertes accidentales. Al mismo tiempo, en el principal periódico de su grupo mediático una periodista, Mónica Báez, recibe información privilegiada que compromete al Gobierno por su ampliación con la venta de armas a Siria. Entre los dos se establece una relación amorosa que sufrirá las decisiones que el protagonista tome y acabará llevando al límite a ella. A continuación, se analizan los resultados siguiendo las líneas marcadas en las preguntas de investigación

\subsection{Personajes}

Los protagonistas visibles son Víctor Genovés y Mónica Báez. Ambos son personajes complejos que sufren una evolución: él un arco de transformación radical 
Gil-Torres, A.

La ficción en búsqueda del realismo. Un análisis de "Los Favoritos de Midas (2020)": periodismo, política y contrapoder

y ella un arco traumático. Los otros protagonistas son Los Favoritos de Midas, pero nunca se conoce su rostro. El resto de los personajes son secundarios o personajes de apoyo que ayudan a la progresión de la trama. Todos ellos se engloban en cuatro grandes categorías: poder y política, periodismo, contrapoder y sociedad/otros. Algunos secundarios cambian de posición como el inspector Conte, que lidera la investigación policial (poder) pero se rebela cuando ve que algo raro sucede (contrapoder), pero la mayoría experimentan un arco de transformación plano que aparecen para dar soporte a la acción.

Poder y política. En este grupo se halla el propio protagonista, el miembro del Banco Nacional que confirma la información sobre la venta de armas a Siria, los miembros de la junta del grupo mediático y los accionistas, Sabino -accionista que al final se debe a la empresa e intereses económicos antes que a la amistad con el protagonista) y la amiga del protagonista, María José Alvar. También la ministra de Interior, el CNI como entidad, el presidente del Gobierno, los que están en la mesa con la ministra y la policía.

Periodismo. La protagonista femenina, el director de El Observador Nacional -el diario buque insigne del grupo y con parecidos con El País-, los tertulianos en los programas de televisión y el periodista imbécil con argumentos débiles.

Contrapoder: Aquí se enmarca Alfaad, el sirio que confiesa todo a la periodista, las revueltas y manifestaciones ciudadanas, Los Favoritos de Midas al inicio -y que al final son poder- y el inspector Conte.

Sociedad/otros. Comprende al resto: la madre que sirve de apoyo emocional y que pide a su hija periodista que no se meta en líos, el chófer que quiere imitar la vida de su jefe, los 7 inocentes que mueren y que se muestra su vida corriente, la exmujer que por dinero renuncia a su hijo o el hijo al que el protagonista no quiere que le pase lo que a él. También el abogado del protagonista, quien le avisa de que su predecesor era un buen conductor, tenía la misma cara que él y a los pocos días murió en un accidente de tráfico-porque quizá estaba siendo chantajeado y no accedió-. Especial atención a Gerardo Pinzón -interpretado por Carmelo Gómez- quien muestra la única salida y en realidad, aunque la serie no lo plantea como tal, implica un cambio de paradigma, una renuncia al dinero y al poder, un cambio del materialismo al holismo.

En cuanto a los tres protagonistas, Víctor Genovés es un hombre español de mediana edad, sano, que supuestamente no tiene vicios, con un físico normal entre la sociedad española -incluso su calvicie está asimilada como un rasgo español ya que nuestro país es el segundo del mundo en número de calvos-. En el ámbito social es un hombre divorciado, con un hijo de 10 años; dirige un grupo mediático y se sitúa en la clase alta. Su marco espacio-temporal es variable ya que experimenta cambios tanto personales como profesionales. En la dimensión psicológica, su personalidad se puede enmarcar como introvertida ya que parece una persona tímida y reservada. Su temperamento se enmarca en la función vital racional por estar anclado a la realidad 
Gil-Torres, A.

La ficción en búsqueda del realismo. Un análisis de "Los Favoritos de Midas (2020)": periodismo, política y contrapoder

y destilar pragmatismo e intuición porque llega a comprender el porqué de los asesinatos. El objetivo de este rol es, principalmente, buscar su propia tranquilidad (incluso hace donaciones a las familias de los asesinados para limpiar su conciencia). El arquetipo que se concreta en este personaje es el de hombre normal que llega al poder por casualidad y que intenta ser padre o rey y mantenerse rebelde (libre sin que nadie le mande). Sufre un arco de transformación radical porque llega a desestabilizar al personaje convirtiéndolo en alguien diferente. Era alguien "bueno" hasta que le entran dudas, pierde la ética y se convierte en uno de "ellos". En cuanto a los estereotipos encontramos que es el hombre de negocios, de personalidad reservada, que está divorciado, no tiene tiempo para su hijo, vive en pleno centro de Madrid en una casa de lujo, personal que le atiende -limpieza y chófer-, que tiene problemas porque le cuestionan su dirección empresarial y que se enamora de una mujer que trabaja para él.

Mónica Báez es una mujer, española, de 30 y muchos años, aparentemente sana, aunque fumadora, y con un físico delgado y guapa. Sociológicamente, es soltera con una buena relación con su madre, a quien acude siempre que tiene dudas o necesita cobijo emocional. Es una periodista profesional con un marco espacio-temporal laboral estable ya que sigue trabajando en el mismo periódico durante toda la ficción y su vida personal apenas evoluciona porque aun cuando se relaciona con el protagonista y vive un poco de su realidad cuando acude a una fiesta, se da cuenta de que eso no es para ella. Psicológicamente es más bien introvertida, pero con ambición. Según la clasificación del temperamento de Jung (2008), tiene un gran "sentir" ya que posee la capacidad de empatía y un alto sentido de lo bueno y lo malo. Su objetivo es la búsqueda de la verdad y ser íntegra con ella misma. Posee una ética y valores intachables. Arriesga su profesión -por publicar la noticia que conecta al Gobierno con Siria y su vida cuando se enfrenta a Los Favoritos de Midas por los principios del periodismo: velar por la verdad y el periodismo íntegro. Acude a platós de televisión para ser la lanza de lo moral (mirar discurso sobre los disturbios). Como periodista, su actividad se enmarca en la investigación y la política (primera esfera), es un drama femenino (segunda) y es una heroína que persigue la verdad, aunque su vida corra peligro (tercera). Su arco de transformación es traumático ya que sufre situaciones que la sacuden internamente generándola conflictos morales. En cuanto a la estereotipación es la mujer que se enamora de su jefe, la idealista en su trabajo que da la vida por lo que cree y la niña que acude a su madre cuando tiene dudas.

Otro de los protagonistas es los llamados Los Favoritos de Midas. Nunca se llega a saber quiénes son, pero su protagonismo es manifiesto. Son los que ponen en jaque al rol masculino y adoptan el papel de antagonista principal. Se estereotipan como el "mal", los que controlan todo a la sombra, saben cada movimiento del protagonista y no les importa sacrificar vidas humanas con tal de conseguir sus objetivos.

En la ficción, la categorización mediante los estereotipos es un recurso necesario para poder identificar, clasificar, generalizar y absorber de la realidad los datos más importantes. La simplificación de los atributos psicológicos de los personajes se 
Gil-Torres, A.

La ficción en búsqueda del realismo. Un análisis de "Los Favoritos de Midas (2020)": periodismo, política y contrapoder

convierte en un recurso práctico y rápido para que el público les comprenda ágilmente y su conducta o proceder sea imaginable. De esta manera se perpetúan estereotipos sobre grupos sociales. En este caso podemos observar cómo la junta es perversa, el padre es bueno, la periodista es profesional, la clase política es mala, el policía que desconfía de todo y que se transforma en bueno... Según Martínez i Surinyac (1998) y Galán Fajardo (2006), los estereotipos también pueden servir como apoyo para los personajes que aparecen en un breve lapso de la historia en los que su aparición se explica más por su relación con el personaje principal y menos por la trama en sí (personajes de apoyo). Esto se percibe en la madre que le da consejos a la hija periodista, el hijo que rechaza a su padre porque éste está muy ocupado presidiendo el grupo mediático, el amigo que traiciona al protagonista o la amiga exitosa que le ayuda.

\subsection{Escenarios}

Se opta por escenarios muy conocidos o familiares. Esto se aprecia desde un primer momento con la zona de negocios de las 4 torres (CTBA), donde está ubicado el despacho y sede del grupo mediático: Castellana 259. Otra dirección conocida es la Calle Serrano 22, donde se localiza la casa de Mónica Baéz. Es una calle emblemática que cualquiera reconoce por su nombre aun sin apenas tener conocimientos de Madrid. El protagonista masculino vive en la Calle Gran Vía, 27. Aquí se le ve llegando a su casa y un conocido comercio detrás. En cuanto a la casa familiar de Víctor Genovés en la que vive su exmujer e hijo aparece en otras series españolas como Élite o el Nudo y está ubicada en la Calle Cabo Ortegal 24 en Las Rozas, al lado del club de Golf Madrid SD.
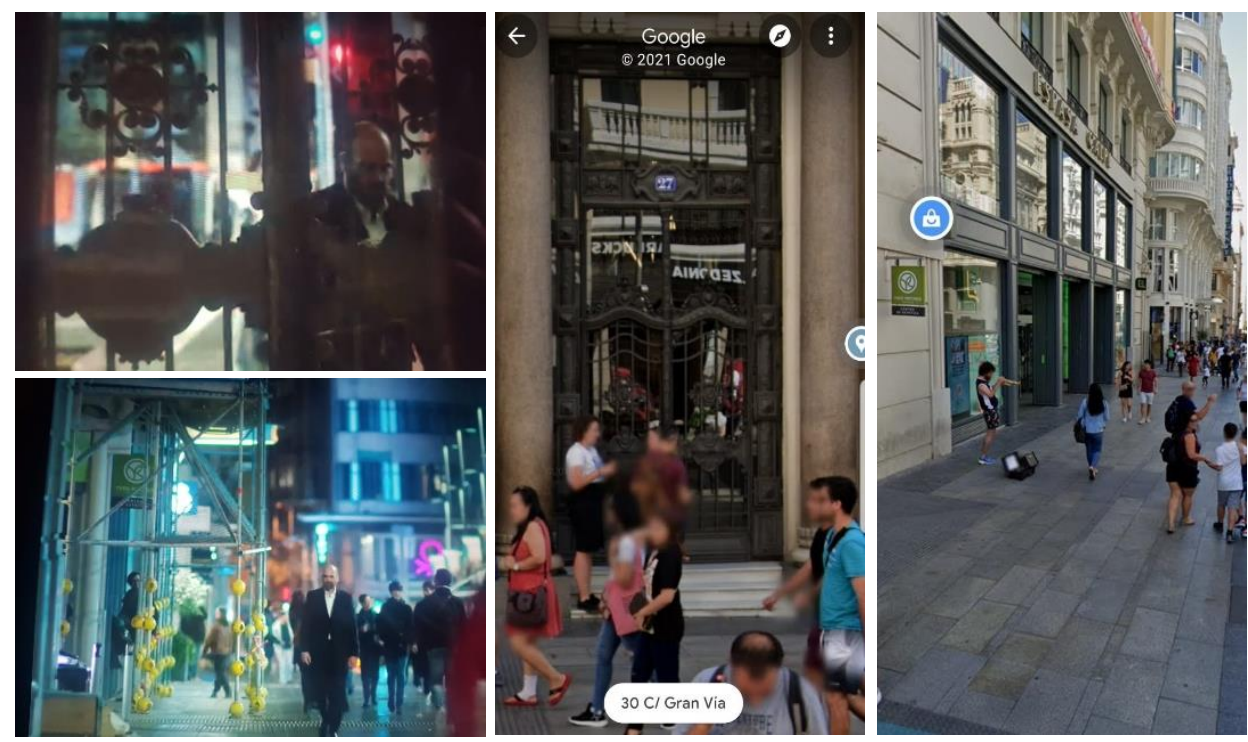

Figura 2: Ubicación de la casa del protagonista

Fuente: Netflix y Google Maps 
Gil-Torres, A.

La ficción en búsqueda del realismo. Un análisis de "Los Favoritos de Midas (2020)": periodismo, política y contrapoder

Hay otros lugares en los que se desarrolla la acción que no se conoce su sitio real, como la comisaría, la casa de la madre de la periodista o la primera cena del protagonista con su amiga José. Otros, los emulan por dentro, como el ministerio del Interior o Siria. Incluso la excursión a Segovia podría ser esa provincia o la misma Comunidad de Madrid.

Respecto a los lugares en los que cometen los asesinatos, el primero, el del atropello a la madre de familia, tiene lugar en la avenida de Nuestra Señora de Valvaneda (figura 3), en Carabanchel, un barrio humilde como se aprecia en la vivienda que muestra. El segundo homicidio, el de la muerte del falso francotirador, tiene lugar detrás del cine de Ópera, en la calle Costanilla de los Ángeles. Así lo dicen en la serie y se comprueba que coincide con la ubicación. La tercera persona muerta es una chica a la que se le cae el andamio de una fachada. Ocurre en la calle Tribulete, que sale de la plaza de Lavapiés (figura 3). Esta localización es fácilmente identificable porque muestra la propia plaza y la muy reconocible fachada de la UNED.
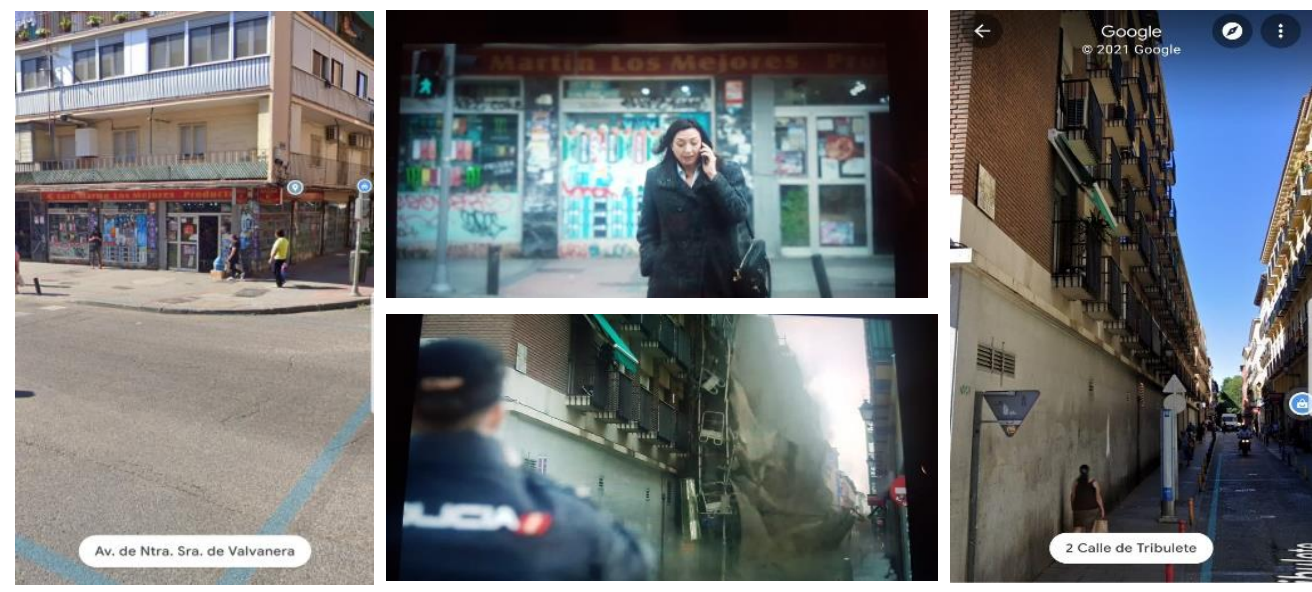

Figura 2: Localización primer y tercer asesinato

Fuente: Netflix y Google maps

El cuarto crimen, el del manifestante, sucede en el Paseo del Prado, entre las plazas de Cibeles y Neptuno. El niño que se cae desde la azotea es el quinto asesinato. Sucede mientras el protagonista está comiendo en un restaurante que existe en realidad: Montes de Galicia en la calle Azcona, 46. El sexto asesinato corresponde a un hombre al que envenenan del que policía sospechaba por la muerte del manifestante y del niño. En la serie indican que es la calle Bronce 146, pero no coincide con la realidad. Sin embargo, gracias a la imagen de un concesionario que se aprecia desde la ventana en la que está el gato apoyado, se comprueba que en realidad es Bronce 14. 
Gil-Torres, A.

La ficción en búsqueda del realismo. Un análisis de "Los Favoritos de Midas (2020)":

periodismo, política y contrapoder
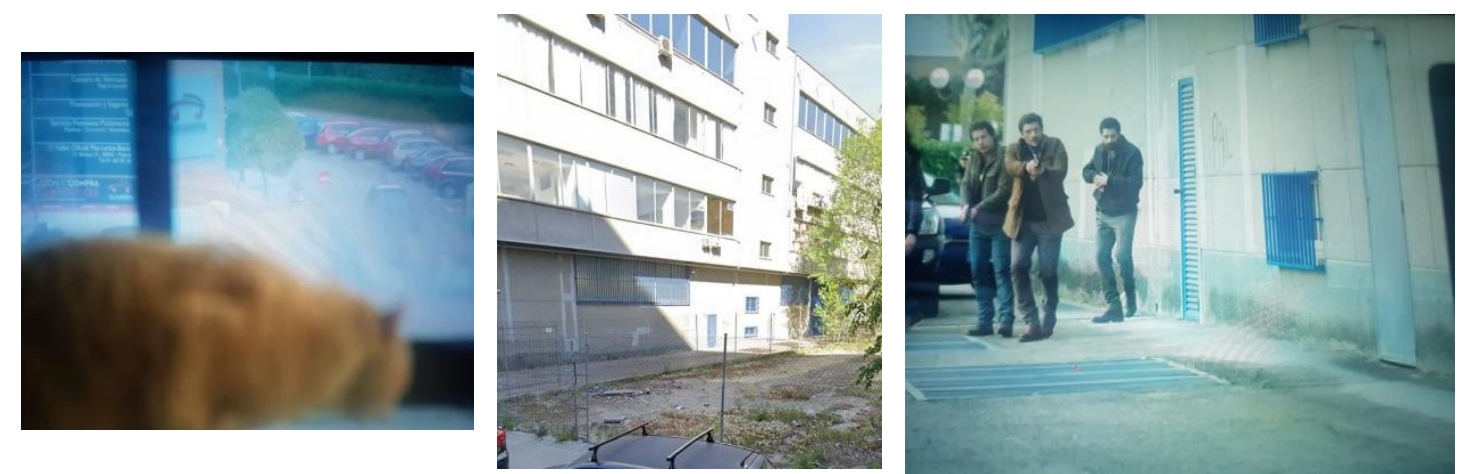

Figura 4: Ubicación sexto asesinato

Fuente: Netflix y Google Maps

El último crimen se perpetua en la Dehesa de la Villa. Aunque cuando el comisario Conte muestra la imagen del registro del GPS del protagonista apareciendo en esta el texto de Dehesa de la Villa, se confirma que dicha imagen corresponde en realidad al Parque del Oeste. No obstante, la secuencia del asesinato sí está rodado en el parque de La Dehesa de la Villa, aunque la imagen mostrada por el policía sea la del Parque del Oeste.
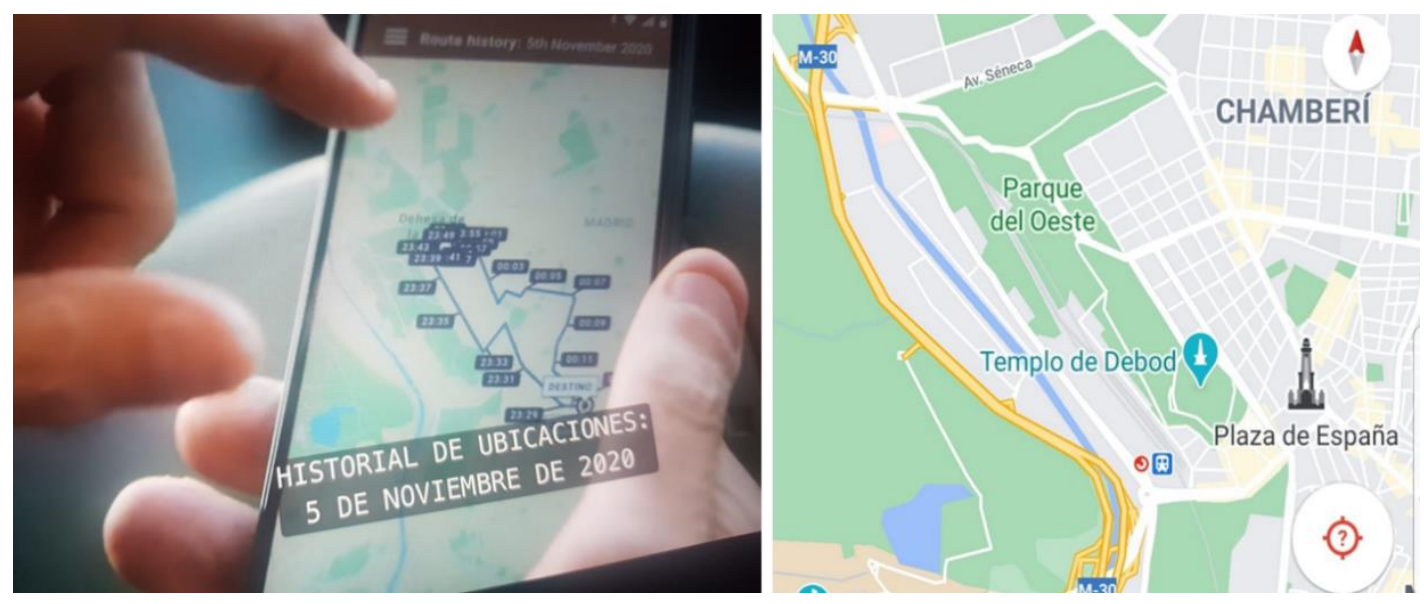

Figura 5: Simulación escenario séptimo asesinato

Fuente: Netflix y Google Maps

\subsection{Contexto}

Desde los años 90, en las series de ficción en España es recurrente el empleo de noticias de prensa, en parte por el contenido dramático y también por las posibilidades que ofrecen a los protagonistas por los sucesos y conflictos concernientes al contexto social de estas noticias (Galán Fajardo, 2006). Lo primero que se percibe es que se elige un país real donde se desarrolla toda la trama: España. Esta elección permite dotar de cercanía a todas las acciones. Otro contexto actual y reconocible, aunque sea solo porque durante años suena en los informativos es Siria. Emplean una guerra real para enmarcar la venta de armas por parte del gobierno -hecho que ya se destapó con el 
Gil-Torres, A.

La ficción en búsqueda del realismo. Un análisis de "Los Favoritos de Midas (2020)": periodismo, política y contrapoder

suministro de material militar a Arabia Saudí, Marruecos, Turquía, Venezuela o Irán-

Otro tejido con el que la sociedad española está familiarizada son las manifestaciones y esas muestras de polarización en las calles. Desde el movimiento $15 \mathrm{M}$ (2011) se han producido las expresiones públicas tomando la calle en numerosas ocasiones con motivo del descontento social por el inminente colapso del estado del bienestar. En muchas de ellas, la existencia de violencia y la presencia de la policía y los antidisturbios no es un elemento positivo, sobre todo desde los recortes -sanitarios, económicos o sociales-, las medidas del confinamiento por la COVID-19 o la aprobación de la ley Mordaza que limita la libertad de expresión. En la miniserie tiene su reflejo en la brutalidad policial en las manifestaciones, donde esta acaba ampliando la amenaza de Los Favoritos de Midas en una muerte más.

Otro contexto importante es el periodismo, apreciable desde la publicación de la noticia de que España vende armas a Siria y que remueve a la sociedad hasta la intención de destapar la extorsión de Los Favoritos de Midas. Los periodistas son protagonistas, influenciadores y modificadores. A su vez, es un elemento de contrapoder, dominante y que posee unos estándares éticos importantes, hecho que se puede observar encarnado en el papel principal de la periodista de Mónica Báez. Esto sigue la estela de la tesis defendida por San José-de la Rosa; Miguel-Borrás; Gil-Torres (2020). Dentro de este ambiente, el protagonista es el diario El Observador Nacional, buque insignia del grupo mediático y la lucha por su supervivencia en un entorno hostil que no vela por los valores del periodismo. Al hilo de este contexto se hallan las relaciones entre medios de comunicación y poder con el pacto no escrito de no agresión. Esto se entiende que existe hoy día por lo descafeinado de los medios y ya apenas son un elemento de contrapoder.

\subsection{Acciones}

A lo largo de la historia se pueden encontrar diversas acciones que tejen la trama agrupadas en las siguientes esferas:

\section{Periodísticas}

1. Sistema de publicación, ejemplificado con la noticia de Siria y el dilema de publicarla o no.

2. Las tertulias de televisión donde cuenta el infoentretenimiento y la opinión.

3. Las repercusiones en otros medios que tiene la primicia de Siria.

4. Las ruedas de prensa de la ministra

5. Las noticias de los disturbios y la actuación policial.

6. La fusión final de medios y su gran despliegue en una campaña mediática.

7. La importancia de los blogs como alternativas: intención de Mónica Báez de publicar en su blog la extorsión de Los Favoritos de Midas. 
Gil-Torres, A.

La ficción en búsqueda del realismo. Un análisis de "Los Favoritos de Midas (2020)": periodismo, política y contrapoder

\section{Política y poder}

1. Las apariciones de la ministra Interior y sus ruedas de prensa.

2. La reunión secreta en el Ministerio de Interior para que el protagonista deje de investigar. Le coaccionan para que desde ese momento lo entienda como muertes casuales y no homicidios.

3. Mostar cómo el presidente del Gobierno recibe a los líderes de las manifestaciones, aunque no lleguen a acuerdo alguno.

4. El hombre que trabaja para el Banco Central que confirma la venta de armas a Siria.

5. Las repercusiones en Bolsa cuando publica noticia con la caída de las acciones.

6. Los envíos de sobres lacrados por parte de los FdM.

7. Las reuniones de la junta para ejercer control sobre el protagonista.

8. El primer evento con accionistas donde habla de la importancia de la seguridad y el segundo, donde incide en la fusión por sorpresa.

9. Las acciones de la policía en manifestaciones que dan lugar al asesinato de un civil.

10. La macrofiesta de José Alvar donde acude la clase alta y se muestra sin tapujos cómo se subastan personas, despilfarro y elitismo.

11. La oferta de cambio de grupo mediático que le ofrece Jose a Víctor Genovés que muestra cómo un cambio de línea editorial es sencillo.

12. La fiesta en la casa -de nuevo- de Víctor Genovés en la que están las personas influyentes para darle la enhorabuena.

13. El remordimiento por la muerte de las víctimas inocentes subsanado con un desembolso de dinero anónimo a las familias de las víctimas muestra cómo el poder lo quiere tapar con dinero.

14. Los pagos a los FdM. El primero lo realiza por egoísmo, sólo lo efectúa para que le dejen en paz; y el segundo, por orgullo y soberbia, no quiere dejarles ganar.

15. El tiro en la Dehesa a la séptima víctima indefensa es un mensaje a los FdM para decirles que él tiene el poder de decidir y ellos ya no le manipulan.

16. El posterior engaño a Mónica al dice que ha pagado y en verdad ha asesinado.

17. La aparición del coche que aparece para buscar al protagonista y el último email.

\section{Contrapoder}

1. El viaje a Siria de la protagonista para descubrir información relativa al Gobierno.

2. Las revueltas por el mantenimiento del estado del bienestar.

3. La tenacidad por querer publicar la noticia de la venta de armas.

4. El robo del USB por parte del inspector Conte cuando llega el CNI como un acto de justicia, junto a seguir investigando por su cuenta y hacer llegar la información a la periodista. 
Gil-Torres, A.

La ficción en búsqueda del realismo. Un análisis de "Los Favoritos de Midas (2020)": periodismo, politica y contrapoder

5. La entrevista a Gerardo Pinzón, otro "nuevo rico" que fue chantajeado a quien la periodista le dice que no está solo si quiere luchar contra ellos, pero este prefiere seguir en el holismo.

\section{Sociedad/Otros}

1. Las manifestaciones que se suceden a lo largo de los capítulos.

2. El chofer irrumpe en la casa del protagonista para llevar a sus ligues para impresionarlas cuando este no se encuentra allí.

3. La relación sentimental/sexual de los protagonistas: ella se enamora de su jefe.

4. El clásico de la relación madre/hija donde esta acude a su progenitora como refugio emocional.

5. La reiterada relación padre/hijo donde al comienzo apenas existe y poco a poco se va fortaleciendo con actividades comunes

6. La humanización de las muertes: cada vez que alguna persona era asesinada se mostraba parte de su vida. Eran personas normales a los que les podían pasar sucesos mortales.

Todas estas acciones localizadas son las que, basadas en los contextos, ejecutadas por los personajes y entrelazadas, dan forma a la miniserie. Algunas de ellas -la relación distante del padre con su hijo; el chófer que queriendo saborear el poder hace uso de la casa de su jefe; la historia de amor entre el jefe y la subordinada; o las fiestas para la clase alta- caen en estereotipos. Otros son fácilmente reconocibles por estar familiarizados con ellos ya sea por experiencia propia o por verlas constantemente en el cine o la televisión: ruedas de prensa de políticos, revueltas, presencia en platós de televisión, acciones cotidianas que realizan las víctimas antes de morir o las operaciones policiales, por ejemplo.

\section{DISCUSIÓN Y CONCLUSIONES}

Después de analizar la miniserie se percibe que se ha creado una ficción a imagen y semejanza de la realidad; en parte porque los guionistas ven la televisión, leen noticias, están en redes sociales, etc., y, aunque sea de manera inconsciente, beben y se inspiran en los contextos y situaciones de la vida misma para extraer tramas argumentales y plasmarlos en el producto audiovisual. Esto perpetúa los temas y personajes estereotipados porque son estos los que mejor se prestan a su dramatización para enganchar al espectador. En Los favoritos de Midas se encuentra la guerra de Siria, las luchas de poder por las presidencias en grupos mediáticos, la policía frente a manifestantes, la mano invisible detrás de los gobiernos y, por supuesto, una historia de amor como telón de fondo. De esta manera, cuando se contrasta la ficción y la realidad, el paralelismo es evidente a la vez que se descubre la función de economía en la relación entre individuo y contexto al simplificar el proceso de los estereotipos. De esta manera se detecta el rico que vive en la céntrica Gran Vía, divorciado porque trabaja tanto que no puede dedicar tiempo suficiente a su familia (incompatibilidad de ser millonario con vida familiar), su hijo hace esgrima (deporte poco común) y que su 
Gil-Torres, A.

La ficción en búsqueda del realismo. Un análisis de "Los Favoritos de Midas (2020)": periodismo, politica y contrapoder

exmujer renuncia al hijo por dinero; la periodista curiosa que vela por salvaguardar los valores éticos pero se enamora de su jefe; el chófer, persona de confianza, que le traiciona; el policía que se rebela contra el sistema o el amigo de la junta que le traicionó. Incluso las personas que son asesinadas tenían una vida corriente que se muestra y en la que muchos espectadores pueden verse reflejados.

Respecto a los escenarios, algunos se constatan que son reales y reconocibles fácilmente por el espectador y otros, al no disponer de la información pertinente, no se puede confirmar como, por ejemplo, cuando indican que van Segovia. Acerca de los contextos, el nombrar al país y no dejarlo a la imaginación del espectador ayuda a situar el argumento y asimilar fácilmente los acontecimientos que suceden. Este es el caso del diario El Observador Nacional en la ficción, buque insignia del grupo mediático y la lucha por su supervivencia en un entorno hostil que vela por regresar a los valores del periodismo, hace pensar en El País en algún momento.

Del análisis de las acciones se descubre la existencia de dos dimensiones paralelas que difícilmente se tocan: las altas esferas del poder y las más mundanas con sus luchas diarias. Se descubre la existencia del clásico "el bien contra el mal" o "los valores y ética versus corrupción" con una crítica a un sistema descompuesto que llega a empapar al periodismo, ese verdadero contrapoder o vigilante del poder. Y lo interesante es que todo está ligado de alguna manera al periodismo, elemento de unión, a veces imperceptible por lo asumido que tenemos su presencia en nuestras vidas, de los contextos, acciones y personajes. De esta forma, se corrobora la $\mathrm{H}_{2}$.

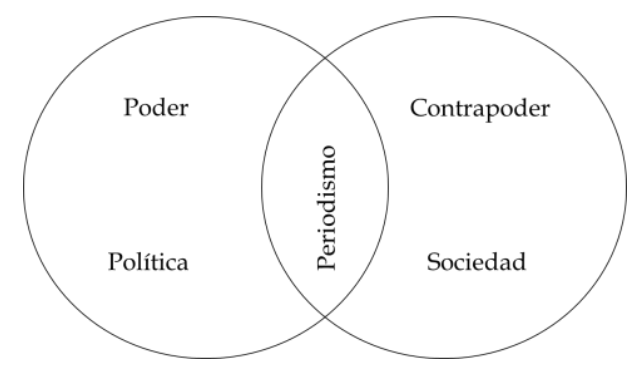

Figura 6: Periodismo como contexto convergente de las acciones Fuente: elaboración propia

La historia elegida no es novedosa ya que contiene elementos manidos como extorsión, aspiraciones de poder, imperio mediático, problemas familiares, líos amorosos, conflicto social o asesinatos. Sin embrago son estos patrones de la realidad los mismos que confirman la $\mathrm{H}_{1}$ planteada de que la ficción necesita apoyarse en marcos reales existente en la vida real para la creación de un contexto y personajes que simulen una verdad para lograr un mayor éxito.

Por ello -y recordando el efecto de realidad y la teoría del reflejo-, el contexto histórico-social y la presentación del escenario mostrado de una España no demasiado distópica es identificable y admitido porque la ficción de Los favoritos de Midas ha 
Gil-Torres, A.

La ficción en búsqueda del realismo. Un análisis de "Los Favoritos de Midas (2020)": periodismo, política y contrapoder

generado su realidad basándose en unas demostraciones preexistentes de la sociedad adecuándolas al lenguaje audiovisual. De esta manera, aunque se representen estereotipos y algún tema manido, la realidad mostrada en la ficción se ajusta bien a su referente real del momento.

Con esta primera aproximación se pretende contribuir humildemente al campo de la incursión de la realidad en la ficción española. A través de una metodología que combina las aportaciones previas de autores centrados exclusivamente en el análisis de los personajes con las propuestas metodológicas de la autora se ha logrado identificar la relación espacio-tiempo y las acciones que definen cómo la ficción dota de realismo a sus narrativas. A pesar de las limitaciones iniciales por ser empelado este método en una serie únicamente, no se descarta su replicabilidad futura para comprobar su eficacia o corregir errores que puedan surgir.

\section{REFERENCIAS}

Agapito-Mesta, C. (2016). Los arquetipos como herramientas para la construcción de buenas historias: análisis del universo diegético de intensamente (tesis doctoral). Universidad de Piura, Perú. https://hdl.handle.net/11042/2587

Audiovisual451 (2019). La oportunidad de los contenidos de ficción en España. Análisis de oportunidad realizado por PwC. https://www.audiovisual451.com/wpcontent/uploads/2019/03/La-oportunidad-de-los-contenidos-de-ficcion-enEspa \%C3\%B1a.pdf

Barthes, R. (1994) El susurro del lenguaje. Más allá de la palabra y de la escritura. Paidós.

Bejerano, P. G. (2020). Cinco años de Netflix: el impacto en la producción audiovisual española. Retina, El País https://retina.elpais.com/retina/2020/10/16/innovacion/1602843710_314589.ht $\underline{\mathrm{ml}}$

Bermejo, J., y Núñez, M. (2008) Valores y actitudes de los espectadores de series de ficción televisiva. Presentado en actas de I Congreso de la AE-IC Investigar La Comunicación. Santiago De Compostela, 35-55.

Chicago Tribune (2009). ER and County General. Chicago Tribune, 31 marzo 2009. https://www.chicagotribune.com/news/ct-xpm-2009-03-31-0903300385story.html

Comelles, J. M. y Brigidi, S. (2016) Etnografía, realidad y ficción en médicos y enfermeras en las series de televisión. En Brigidi, S. (ed). Cultura, salud, cine y televisión. Recursos audiovisuales en Ciencias de la Salud y Sociales, pp. 225-255. Tarragona: URV. 
Gil-Torres, A.

La ficción en búsqueda del realismo. Un análisis de "Los Favoritos de Midas (2020)": periodismo, politica y contrapoder

$\begin{array}{lllll}\text { Digital TV } & \text { (2020). } & \text { October }\end{array}$ https://www.digitaltvresearch.com/ugc/press/254.pdf

Dimaggio, M. (1992). Escribir para televisión. Cómo elaborar guiones y promocionarlos en las cadenas públicas y privadas. Paidós Comunicación.

Durkheim, E. (2016). Las reglas del método sociológico. Madrid: Alianza Editorial

Egri, L. (1946). The Art of Dramatic Writting. Its basis in the creative interpretation of human movies. Touchstone Book.

Fernández, F., y Bassiner, J. (1996). Arte y técnica del guion. Universidad Politécnica de Catalunya.

Field, S. (1984). El manual del guionista. Ejercicios e instrucciones para escribir un buen guión paso a paso. Plot Ediciones.

Galán, E. (2006). Personajes, estereotipos y representaciones sociales. Una propuesta de estudio y análisis de la ficción televisiva. ECO-PÓS, 6(1), 58-81. http://hdl.handle.net/10016/9475

Glevarec, H. (2010). Trouble dans la fiction. Effets de réel dans les séries télévisées contemporaines et post-télévision. Questions de communication, 18, 214-238. https://doi.org/10.4000/questionsdecommunication.405

González, B. (1999). Los estereotipos como factor de socialización en el género. Revista Comunicar (12), 79-88. https:/ / doi.org/10.3916/C12-1999-12

Grossocordón Cortecero, C. (2019). Propuesta metodológica sobre análisis de personajes en el relato cinematográfico: Caso práctico: La filmografía actoral de $\begin{array}{llll}\text { Clint Eastwood. Communication } \mathcal{E} \text { Methods, } & \text { 1, }\end{array}$ https://doi.org/10.35951/v1i1.18

Jung, C. (2008). Tipos psicológicos. Barcelona: Ediciones Edhasa.

Malgesini, G., y Giménez Romero, C. (2000). Guía de conceptos sobre migraciones, racismo e interculturalidad. Madrid: Los Libros de la Catarata.

Martínez i Surinyac, G. (1998). El guión del guionista. El desarrollo del guión desde la idea hasta el guión literario. Editorial Cims 97.

Moscovici, S. (ed.) (1986). Psicología social, II. Pensamiento y vida social. Psicología social y problemas sociales. Paidós. 
Gil-Torres, A.

La ficción en búsqueda del realismo. Un análisis de "Los Favoritos de Midas (2020)": periodismo, política y contrapoder

Moscovici, S. y Hewstone (1986). "De la ciencia al sentido común”. En Moscovici, S. (ed.). Psicología social, II. Pensamiento y vida social. Psicología social y problemas sociales, 679-710. Paidós.

Neira, E. (2020). Streaming Wars. La nueva televisión. Barcelona: Libros Cúpula.

Padilla Pineda, M. (1990). Durkheim y la formación social de la subjetividad. Sociología, 5(14), 91-108

Propp, V. (1971). Morfología del cuento. Editorial Fundamentos.

Rodríguez Salazar, T. (2015). Sobre el potencial teórico de las representaciones sociales en el campo de la comunicación. Comunicación y Sociedad, 11, 11-36. https://doi.org/10.32870/cys.v0i11.1792

San José de la Rosa, C. (2017). “El perfil del periodista en el cine español (1942-2012)" (Tesis doctoral). Universidad de Valladolid, España. Sin acceso.

You, M., \& Ju, Y. (2019). Salience of public leaders' "meaning making" in news coverage of a health crisis. Journal of Contingencies and Crisis Management, 27(4), 400405. https://doi.org/10.1111/1468-5973.12259

San José-de la Rosa, C., y Gil-Torres, A. (2019). Cine para aprender: de los cuentos de Vladimir Propp a las películas españolas con periodistas. Caracteres: estudios culturales y críticos de la esfera digital, 8(2), 42-66.

Seger, L. (1990). Cómo crear personajes inolvidables. Guía práctica para el desarrollo de personajes en cine, televisión, publicidad, novelas y narraciones cortas. Editorial Paidós.

Seger, L. (1999). Cómo convertir un buen guión en un guión excelente. Ediciones Rialp.

Tajfel, H. (1984). Grupos humanos y categorías sociales. Editorial Herder.

\section{AUTOR/ES:}

\section{Alicia Gil-Torres}

Doctora en Periodismo (Premio Extraordinario), Máster en Consultoría Política, Licenciada en Publicidad y Relaciones Públicas y Graduada en Periodismo. Profesora Ayudante Doctor en la Universidad de Valladolid en el grado de Periodismo. Miembro del proyecto de investigación «Politainment en el entorno de la posverdad: nuevas narrativas, clickbait y gamificación» y del GIR Nuteco. Estancias como profesora en universidades de Estados Unidos, Sudáfrica, Alemania, y Grecia. Sus líneas de investigación son comunicación política, campañas electorales y comunicación organizacional. 
Gil-Torres, A.

La ficción en búsqueda del realismo. Un análisis de "Los Favoritos de Midas (2020)": periodismo, política y contrapoder

Orcid ID: http:// orcid.org/0000-0002-8042-2208

Google Scholar: https://scholar.google.es/citations?user=sYmJrS4AAAAJ\&hl=es

ResearchGate: https://www.researchgate.net/profile/Alicia_Gil-Torres

Scopus ID: https:/ / www.scopus.com/authid/detail.uri?authorId=57195761187

Academia.edu: https://uva-es.academia.edu/AGilTorres 